九州大学学術情報リポジトリ

Kyushu University Institutional Repository

\title{
A Study on Fatty Acid Analysis as a New Taxonomic Tool for Differentiating Rhizoctonia Spp.
}

Matsumoto, Masaru

Laboratory of Plant Pathology, Faculty of Agriculture, Kyushu University

Furuya, Naruto

Laboratory of Plant Pathology, Faculty of Agriculture, Kyushu University

Takanami, Yoichi

Laboratory of Plant Pathology, Faculty of Agriculture, Kyushu University

Matsuyama, Nobuaki

Laboratory of Plant Pathology, Faculty of Agriculture, Kyushu University

https://doi.org/10.5109/24114

出版情報：九州大学大学院農学研究院紀要. 40 (3/4)，pp.279-286，1996-03. Kyushu University バージョン：

権利関係 : 


\title{
A Study on Fatty Acid Analysis as a New Taxonomic Tool for Differentiating Rhizoctonia Spp.

\author{
Masaru Matsumoto, Naruto Furuya, Yoichi Takanami \\ and Nobuaki Matsuyama
}

\author{
Laboratory of Plant Pathology, Faculty of Agriculture, \\ Kyushu University, Fukuoka 812-81, Japan \\ (Received October 24, 1995)
}

\begin{abstract}
Fatty acid composition of three species of Rhizoctonia and seven anastomosis groups including twelve intraspecific groups of $R$. solani was studied by gas-liquid chromatography. The major fatty acids identified were palmitic, palmitoleic, oleic and linoleic acids, which constituted 92.1-96.0\% of the whole-cell fatty acids identified. A dendrogram of the three Rhizoctonia spp. showed that the isolates of $R$. solani and $R$. candida are closely related in fatty acid composition, whereas the isolates of $R$. oryzae were more distantly related with them. In addition, each of the anastomosis groups and intraspecific groups of $R$. solani was divided into individual clusters by dendrogram analysis. All of the intraspecific groups belonging to the AG-1 and AG-2 were differentiated by cluster analysis based on the percent compositions of fatty acids identified. No correlation could be obtained on the dendrogram of $R$. solani isolates on the fatty acid composition and pathogenicity on their respective hosts. However, this technique clearly differentiated Rhizoctonia spp. and especially of anastomosis groups and intraspecific groups of $R$. solani. These works clearly suggested that the fatty acid analysis will be used as one of the taxonomic tools in differentiating Rhizoctonia spp.
\end{abstract}

\section{INTRODUCTION}

Fungi is generally classified by their morphological characteristics. However, insufficient morphological features of the genus Rhixoctonia have led to the complexity and confusion in their nomenclature as well as taxonomic classification. Rhixoctonia solani Kuhn (teleomorph= Thanatephorus cucumeris (Frank) Donk) has wide and overlapping range of isolates with varied morphology, physiology and pathogenicity (Adams, 1988). Attempts to distinguish $R$. solani isolates into logical grouping are based on either hyphal anastomosis and differences in pathogenicity (Ogoshi, 1976; 1987) or the morphological and cultural characteristics (Jones and Belmar, 1989; Sherwood, 1969; Watanabe and Matsuda, 1966).

Hyphal anastomosis in $R$. solani was first reported by Matsumoto (1921). Currently, 10 anastomosis groups (AGs) of $R$. solani are recognized (Carling et al., 1987; Ogoshi, 1987; Ogoshi et al., 1990), and are further divided into subgroups (intraspecific groups: ISGs) based on anastomosis frequency (Ogoshi, 1976) and thiamine requirement (Ogoshi and Ui, 1979; Sherwood, 1969). Ogoshi (1975; 1987) suggested that R. solani could also be differentiated based on their genetic characteristics including isozyme patterns (Matsuyama et al.,1978), DNA base composition (Kuninaga and Yokosawa, 1980), DNA base sequence homology (Vilgalys, 1988), and ribosomal DNA fragment length polymorphisms (RFLPs) techniques (Vilgalys and Gonzalez, 1990). 
Unique whole-cell fatty acid profiles have been used to classify closely related strains of bacterial plant pathogens (De Boer and Sasser, 1986; Graham et al., 1990). However, it has not been used to classify closely related isolates of fungi (Gottlieb and Van Etten, 1966). In plant pathogenic bacteria, the genus and species can be distinguished by qualitative and quantitative differences in fatty acid contents (Gitaitis and Beaver, 1990; Maas et al., 1985). Recently, Stevens Johnk and Jones (1992; 1993; 1994) reported the comparison of whole-cell fatty acid composition in ISGs of R. solani. They also concluded that fatty acid analysis can be used as one of the tools to differentiate pathological types within AGs of $R$. solani.

In the present study the usefulness of fatty acid analysis for classification of Rhixoctonia spp. and the AGs of $R$. solani was discussed.

\section{MATERIALS AND METHODS}

\section{Fungal isolates}

Thirty-six isolates of $R$. solani, eight isolates of $R$. oryzae, and two isolates of $R$. candida were used in this study (Table 1). Each isolate was maintained on a slant culture of potato-dextrose agar (Funakoshi Chem. Co.) amended with $50 \mathrm{mg} / \mathrm{L}$ streptomycin sulfate at $25^{\circ} \mathrm{C}$ in the dark. To prepare samples for fatty acid analysis, each isolate was cultured without shaking in $100 \mathrm{ml}$ of a liquid nutrient-broth medium amended with $50 \mathrm{mg} / \mathrm{L}$ of streptomycin sulfate at $25^{\circ} \mathrm{C}$ for 7 days. After harvest, the mycelia were washed with distilled water, lyophilized and stored at $-20^{\circ} \mathrm{C}$ until use.

\section{Preparation of fatty acid}

Extraction of fatty acid was done according to Gudmastad et al. (1988) with slight modifications. The fatty acids extracted from $10 \mathrm{mg}$ of the lyophilized mycelia were methylated with $0.5 \mathrm{ml}$ of $5 \% \mathrm{HCl}$-methanol at $100^{\circ} \mathrm{C}$ for $3 \mathrm{~h}$ in a sealed glass tube to obtain fatty acid methyl ester (FAME) derivatives. The extract was cooled at room temperature and $1 \mathrm{ml}$ of distilled water was added. The FAMEs were extracted with $2 \mathrm{ml}$ of $n$-hexane by shaking. The solvent phase was washed with an equal volume of distilled water to remove $\mathrm{HCl}$ and dehydrated by mixing with $0.5 \mathrm{mg}$ of anhydrous sodium sulfate. The organic phase was concentrated by nitrogen gas blowing. Samples were stored at $-20^{\circ} \mathrm{C}$.

\section{Fatty acid analysis}

FAMEs were analyzed by a GLC chromatograph (Shimadzu GC 7AG) equipped with a $3 \mathrm{~m} \times 4 \mathrm{~mm}$ DEGS column. The column and injection temperature were maintained at $180^{\circ} \mathrm{C}$ and $250^{\circ} \mathrm{C}$, respectively, and the flow rate of nitrogen gas was $50 \mathrm{ml} / \mathrm{min}$. Three replicated analyses were made for each isolate. Average values of the fatty acid composition were used to differentiate the isolates of Rhixoctonia spp. For each isolate, a data record was constructed in percentages of the respective fatty acids. Relative similarities among isolates were determined by cluster analysis. A resemblance matrix based on Euclidean distance coefficients was computed from pairwise comparison of each isolate with every other isolate based on the analysis of percent fatty acid composition. Dendrogram was constructed by an unweighted paired group method with arithmetic 
Table 1. Isolates of Rhizoctonia spp. analyzed.

\begin{tabular}{|c|c|c|c|}
\hline Isolate & $\mathrm{AG} / \mathrm{ISG}$ & Source & Origin \\
\hline \multicolumn{4}{|l|}{ R. solani } \\
\hline $\mathrm{Cs}-\mathrm{Ka}$ & $1 \mathrm{IA}$ & AHU & Rice \\
\hline C-325 & $1 \mathrm{IA}$ & AKU' & Rice \\
\hline C-326 & $1 \mathrm{IA}$ & $\mathrm{AKU}$ & Rice \\
\hline B-19 & $1 \mathrm{IB}$ & AHU & Sugar beet \\
\hline HK-616-23 & $1 \mathrm{IB}$ & $\mathrm{AKU}$ & Soil \\
\hline RI-86 & $1 \mathrm{IB}$ & $\mathrm{AKU}$ & Sugar beet \\
\hline BV-7 & $1 \mathrm{IC}$ & NIAS ' & Sugar beet \\
\hline $\mathrm{F}-2$ & $1 \mathrm{IC}$ & AHU & Flax \\
\hline P-10 & $1 \mathrm{IC}$ & AHU & Potato \\
\hline PS-4 & $2-1$ & AHU & Pea \\
\hline F-15 & $2-1$ & $\mathrm{AKU}$ & Flax \\
\hline $\mathrm{TG}-1$ & $2-1$ & $\mathrm{AKU}$ & Tulip \\
\hline C-96 & $2-2$ IIIB & M. Oniki & Mat rush \\
\hline c-321 & $2-2$ IIIB & AKLJ & Mat rush \\
\hline C-116 & 2-2 IIIB & AKLJ & Mat rush \\
\hline RI-64 & 2-2 IV & IAES ${ }^{(1]}$ & Sugar beet \\
\hline BV -28 & 2-2 IV & AKLJ & Sugar beet \\
\hline BV -34 & 2-2 IV & AKU & Sugar beet \\
\hline ST-11-6 & 3 & AHU & Potato \\
\hline ST-2 & 3 & $\mathrm{AKU}$ & Potato \\
\hline ST-7 & 3 & $\mathrm{AKU}$ & Potato \\
\hline GM-8 & 4 & $\mathrm{AKU}$ & Soybean \\
\hline HI-822 & 4 & $\mathrm{AKU}$ & soil \\
\hline SN-1 & 4 & $\mathrm{AKU}$ & Soil \\
\hline GM-10 & 5 & $\mathrm{AHU}$ & Soybean \\
\hline $\mathrm{SH}-25$ & & $\mathrm{AKU}$ & Soil \\
\hline SH-26 & 5 & $\mathrm{AKU}$ & soil \\
\hline OHT-1-1 & 6 & S. Kuninaga & Soil \\
\hline NAT-3-1 & 6 & S. Kuninaga & Soil \\
\hline HAM-1-1 & 6 & S. Kuninaga & Soil \\
\hline HO-1556 & & Y. Homma & Soil \\
\hline MAFF 305552 & & Y. Homma & Soil \\
\hline MAFF 305553 & & Y. Homma & Soil \\
\hline AI-1-4 & BI & S. Kuninaga & Soil \\
\hline $\mathrm{CH}-\mathrm{l}-2$ & BI & S. Kuninaga & Soil \\
\hline TE-2-4 & BI & S. Kuninaga & Soil \\
\hline \multicolumn{4}{|l|}{ R. oryzae } \\
\hline$c-505$ & WAG-O & NIAS & Rice \\
\hline $\mathrm{T}-1101$ & WAG-O & $\mathrm{KU}$ & Soil \\
\hline KAES-14 & WAG-O & KAES & Rice \\
\hline M-2122 & WAG-O & KAES & soil \\
\hline $\mathrm{RO}-1$ & WAG-O & $\mathrm{SU}^{\mu}$ & Rice \\
\hline $\mathrm{T}-5112$ & WAG-O & $\mathrm{KU}$ & Soil \\
\hline $\mathrm{T}-5122$ & WAG-O & $\mathrm{KU}$ & Soil \\
\hline $\mathrm{T}-5133$ & WAG-O & $\mathrm{KU}$ & Soil \\
\hline \multicolumn{4}{|l|}{ R. candida } \\
\hline IFO 7032 & AG-A (CAG-2) & $\mathrm{IFO}^{\mathrm{hi}}$ & Strawberry \\
\hline IFO 7033 & AG-A (CAG-2) & IFO & Beet \\
\hline
\end{tabular}

a) AHU: Faculty of Agriculture, Hokkaido University

b) AKU : Faculty of Agriculture, Kyushu University

c) NIAS: National Institute of Agricultural Sciences

d) IAES : Ibaragi Agricultural Experiment Station

e) KU: Faculty of Agriculture, Kagoshima University

f) K A ES : Kagoshima Agricultural Experiment Station

g) SU: Faculty of Agriculture, Saga University

h) IFO: Institute for Fermentation 
averages (UPGMA) using the statistics software package SYSTAT.

\section{RESULTS}

Ten fatty acids were identified and quantified in the isolates of three Rhizoctonia spp. They were myristic (C140), pentadecanoic (C150), palmitic (C160), palmitoleic (C161), heptadecanoic (C170), 9-heptadecenoic (C171), stearic (C180), oleic (C181), linoleic (C182) and one unknown fatty acid. These fatty acids were qualitatively similar, but possess quantitative differences. Fatty acids, $\mathrm{C} 160, \mathrm{Cl} 81$ and $\mathrm{Cl} 82$ were predominant in the three Rhizoctonia spp. and comprised $90.5-95.0 \%$ of the whole-cell fatty acids identified.

Profiles of FAMEs of the whole-cell fatty acids prepared from the three Rhizoctonia spp. were distinct from each other (Table 2). The isolates of $R$. oryzae contained more palmitic and palmitoleic acids than the isolates of $R$. solani and $R$. candida. These observations suggested a close resemblance between isolates of $R$. solani and $R$. candida than between isolates of $R$. solani and $R$. oryzae.

Table 2. Percentage composition of whole-cell fatty acids in the three species of Rhizoctonia

\begin{tabular}{lrrrrrrrrrr} 
Rhizoctonia & \multicolumn{10}{c}{ Composition of fatty acid") } \\
\cline { 2 - 12 } \multicolumn{1}{c}{ spp. } & C140 & C150 & C160 & C161 & C170 & C171 & C180 & C181 & C182 \\
\hline$R$. solani & 1.0 & 0.9 & 7.4 & 1.3 & 0.4 & 0.8 & 1.4 & 10.5 & 74.5 & 1.8 \\
$R$. oryzae & 0.5 & 0.3 & 15.4 & 3.5 & 0.6 & 0.8 & 1.9 & 6.2 & 69.7 & 1.0 \\
$R$. candida & 0.5 & 0.4 & 6.5 & 1.0 & 0.3 & 0.2 & 1.0 & 6.1 & 82.4 & 1.7
\end{tabular}

a) Values represent the means of test isolates, each with three replicates.

- : Unidentified

Table 3. Percentage composition of whole-cell fatty acids in Rhizoctonia solani.

\begin{tabular}{lcccccccccc}
\hline \multirow{2}{*}{ AGs of $R$. solani } & \multicolumn{8}{c}{ Composition of fatty acid" } \\
\cline { 2 - 9 } & C140 & C150 & C160 & C161 & C170 & C171 & C180 & C 1 8 1 & C182 & - \\
\hline AG-1 I A & 1.1 & 0.7 & 9.1 & 2.2 & 0.5 & 1.1 & 1.0 & 9.3 & 73.8 & 1.3 \\
AG-1 I B & 1.3 & 1.0 & 6.8 & 0.7 & 0.6 & 0.4 & 1.3 & 9.5 & 76.1 & 2.4 \\
AG-1 I C & 0.9 & 0.7 & 6.7 & 2.0 & 0.9 & 1.3 & 1.3 & 13.4 & 71.7 & 1.1 \\
AG-2-1 & 0.5 & 1.4 & 6.9 & 1.0 & 0.6 & 2.5 & 1.5 & 10.3 & 73.0 & 2.4 \\
XG-2-2 IIIB & 0.7 & 1.1 & 8.1 & 1.7 & 0.3 & 0.7 & 1.2 & 8.9 & 75.8 & 1.5 \\
XG-2-2 IV & 0.6 & 0.9 & 6.9 & 1.8 & 0.2 & 1.3 & 1.3 & 7.0 & 78.3 & 1.8 \\
AG-3 & 0.6 & 1.4 & 6.4 & 1.3 & 0.4 & 0.7 & 1.1 & 11.5 & 74.1 & 2.6 \\
AG-4 & 1.2 & 0.7 & 7.8 & 1.0 & 0.7 & 0.7 & 2.4 & 10.5 & 73.5 & 1.6 \\
AG-5 & 1.1 & 0.6 & 7.3 & 0.6 & 0.1 & 0.2 & 1.5 & 9.1 & 77.5 & 2.0 \\
XG-6 & 2.5 & 1.3 & 7.1 & 1.6 & 0.4 & 0.6 & 0.6 & 9.5 & 73.6 & 3.0 \\
AG-7 & 0.6 & 1.2 & 8.5 & 1.1 & 0.3 & 0.4 & 1.3 & 14.3 & 70.7 & 1.6 \\
AG-BI & 0.4 & 0.4 & 7.5 & 0.5 & 0.2 & 0.2 & 2.0 & 12.5 & 76.2 & 0.6 \\
\hline
\end{tabular}

a J Values represent the means of test isolates, each with three replicates.

$-:$ Inidentified 


\section{Euclidean distance}

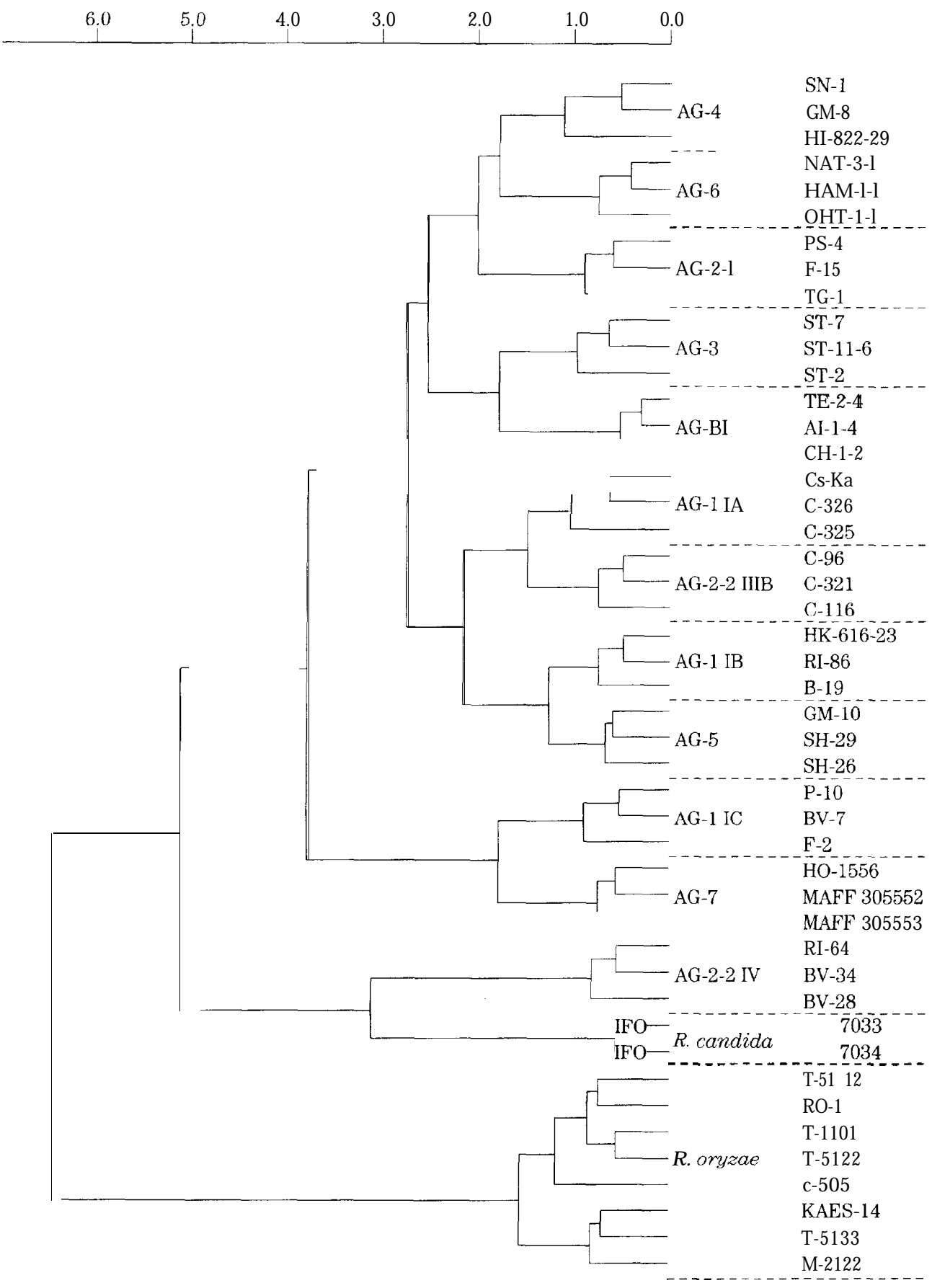

Fig. 1. Dendrogram of cluster analysis on Rhizoctonia species based on the percentage of fatty acid composition. 
The compositions of fatty acids of the various AGs of $R$. solani were shown in Table 3 and Figure 1. The dendrogram analysis gave four major clusters among the AGs of $R$. solani. The AG-4, AG-6, AG-2-1, AG-3 and AG-BI isolates clustered together, with a Euclidean distance of 2.4. The AG-1 IA, AG-2-2 IIIB, AG-1 IB and AG-5 isolates were in another cluster, with a Euclidean distance of 2.3. The AG-1 IC and AG-7 isolates clustered, with a Euclidean distance of 2.1. Interestingly, the AG-2-2 IV isolates were found to be similar with the isolates of $R$. candida, with a Euclidean distance of 3.1. On the other hand, the cluster analysis on the isolates of $R$. oryzae was distinct from those of the isolates of $R$. solani and $R$. candida, with a Euclidean distance of 6.3.

\section{DISCUSSION}

Similar studies indicated that the optimum period of incubation of 4 days cultures on PDA was the best for fatty acid analysis of $R$. solani isolates (Stevens Johnk and Jones, 1993; 1994; Steven Johns et al., 1993). In our preliminary studies, we found no quantitative differences in fatty acid analysis between PDA and the liquid nutrient-broth cultures at 7 days incubation. Therefore, incubation period was fixed at 7 days to ensure sufficient growth of hyphae and to recover larger numbers of fatty acids.

Fatty acid analysis revealed major differences among the three Rhizoctonia spp. The fatty acid composition of the isolates of $R$. solani was similar to that of $R$. candida but was distinct from that of $R$. oryxae isolates. Fatty acid analysis was also shown to be useful to differentiate $R$. solani AGs. Further the qualitative detection of fatty acids \{palmitic (14.5\%), oleic (24.9\%), and linoleic (54.4\%)\} detected supported the finding of Gottlieb and Van Etten (1966). However, the same major fatty acids detected in this study had different composition. Similar study by Stevens Johnk and Jones (1993, 1994) suggested the possibility of differentiating AGs of $R$. solani by fatty acid analysis. However, they described that the fatty acid analysis was not useful in differentiating isolates of AG-1 IA and AG-1 IB and morphological and pathological differences would be necessary to distinguish these ISGs (Stevens Johnk and Jones, 1994). Although the fatty acid composition of the isolates of AG-1 IA and AG-1 IB groups was similar in our study, both of the ISGs were separated into different clusters, with a Euclidean distance of 2.3. In addition, fatty acid analysis of three ISGs of AG-2 isolates, AG-2-1, AG-2-2 IIIB and AG2-2 IV separated them into distinct clusters. Therefore, the results of fatty acid analysis of the ISGs of AG-2 isolates would reflect their grouping based on the morphological and pathological characteristics. These cluster analyses here indicated that the AG-1 IA isolates from rice plant were closely related with the AG-2-2 IIIB isolates from mat rush, with a Euclidean distance of 1.7 (Fig. 1). On the other hand, the fatty acid composition of the AG-1 IB and AG-2-2 IV isolates from sugar beet distinctly differed and the dendrogram analysis gave independent clusters for them (Table 3 and Fig. 1). These results also suggested that fatty acid composition of $R$. solani isolates and their pathogenicity do not always correlate.

In conclusion, fatty acid analysis is useful as a new taxonomic index to classify Rhizoctonia spp. and AGs and ISGs of $R$. solani. Further investigation to develop database library of fatty acid composition for AGs and ISGs of $R$. solani isolates is in 
progress.

\section{ACKNOWLEDGEMENTS}

The authors are grateful to Prof. Dr. A. Ogoshi of Hokkaido University and Dr. S. Naitou of Tohoku National Agricultural Experiment Station for their donation of cultures used in this experiment. The authors also are indebted to Prof. Dr. K. Manibhushan Rao of the University of Madras, India for his helpful suggestion on the preparation of this manuscript.

\section{REFERENCES}

Adams, G. C. Jr. 1988 Thanatephorus cucumeris(Rhizoctonia solani), a specific complex of wide host range. In "Advances in Plant Pathology", Vol. 6, Genetics of Plant Pathogenic Fungi, ed. by G. S. Sidhu, Academic Press, New York, pp. 535-552

Carling, D. E., R. H. Leiner and K.M. Kebler 1987 Characterization of a new anastomosis group (AG-9) of Rhizoctonia solani. Phytopathology, 77: 1609-1612

De Boer, S. H. and M. Sasser 1986 Differentiation of El-winia carotovora subsp. carotovora and E carotovora subsp. atroseptica on the basis of cellular fatty acid compositions. Can. J.Microbiol., 32 : $796-800$

Gitaitis, R. D. and R. W. Beaver 1990 Characterization of fatty acid methyl ester content of Clavibacter michiganensis subsp. michiganensis. Phytopathology, 80: 318-321

Gottlieb, D. and J. L. Van Etten 1966 Changes in fungi with age. I. Chemical composition of Rhizoctonia solani and Sclerotium bataticola. J.Bacteriol., 91: 161-168

Graham, J. H., J. S. Hartung, R. E. Stall and A. R. Chase 1990 Pathological, restriction fragment length polymorphism, and fatty acid profile relationships between Xanthomonas campestris from citrus and non-citrus hosts. Phytopathology, 80: 829-836

Gudmastad, N. C., P. J. Henningson and W. M. Bugbee 1988 Cellular fatty acid composition of strains of Corynebacterium michiganense subsp. sepedonicum from potato and sugar beet. Can. J Microbiol., 34: 716-722

Jones, R. K. and S. B. Belmar 1989 Characterization and pathogenicity of Rhizoctonia spp. isolated from rice, soybean, and other crops grown in rotation with rice in Texas. Plant Dis., 73: 1004-1010

Kuninaga, S and R. Yokosawa 1980 A comparison of DNA base composition among anastomosis groups in Rhizoctonia solani Kiihn Ann. Phytopathol. Soc.Jpn., 48: 659-667

Maas, J. L., M. M. Finney, E. L. Civerolo and M. Sasser 1985 Association of an unusual strain of Xanthomonas campestris with apple. Phytopathology, 75: 438-445

Matsumoto, T. 1921 Studies in the physiology of the fungi. XII. Physiological specialization in Rhizoctonia solani Kiihn. MO. Bot. Gard., 8: 1-62

Matsuyama, N., Z. Moromizato, A. Ogoshi and S. Wakimoto 1978 Grouping Rhizoctonia solani Kiihn with non-specific esterase zymogram. Ann Phytopathol. Soc. Jpn., 44: 652-658

Ogoshi, A 1975 Studies on anastomosis groups of Rhizoctonia solani Kiihn and on their perfect stages. Bull. Natl. Inst. Agric. Sci. Sw. C, 30: l-63

Ogoshi, A 1987 Ecology and pathogenicity of anastomosis and intraspecific groups of Rhizoctonia solani Kiihn. Ann. Rev. Phytopathol, 25: 125-143

Ogoshi, A. and T. Ui 1979 Specificity in vitamin requirement among anastomosis groups of Rhizoctonia solani Kiihn. Ann. Phytopathol. Soc.Jpn., 45: 45-53

Ogoshi, A., R. J. Cook and E. N. Bassett 1990 Rhizoctonia species and anastomosis group causing root rot of wheat and barley in the Pacific Northwest. Phytopathology, 80: 784-788

Sherwood, R. T. 1969 Morphology and physiology in four anastomosis groups of Thanatephorus 
cucumeris. Phytopathology, 59: 1924-1929

Stevens Johnk, J. and R. K. Jones 1992 Determination of whole-cell fatty acids in isolates of Rhizoctonia solani AG-1 IA. Phytopathology, 82: 68-72

Stevens Johnk, J. and R. K. Jones 1993 Differentiation of population of AG-2-2 of Rhizoctonia solani by analysis of cellular fatty acids. Phytopathology, 83: 278-283

Stevens Johnk, J., R. K. Jones, H. D. Shew and D. E. Carling 1993 Characterization of populations of Rhizoctonia solani AG-3 from potato and tobacco. Phytopathology, 83: 854-858

Stevens Johnk, J. and R. K. Jones 1994 Comparison of whole-cell fatty acid compositions in intraspecific groups of Rhizoctonia solani AG-1. Phytopathology, 84: 271-275

Vilgalys, R. 1988 Genetic relatedness among anastomosis groups in Rhizoctonia as measured by DNA/DNA hybridization. Phytopathology, 78: 698-702

Vilgalys, R. and D. Gonzalez 1990 Ribosomal DNA restriction fragment length polymorphisms in Rhizoctonia solani. Phytopathology, 80:151-158

Watanabe, B. and A. Matsuda 1966 Studies on the grouping of Rhizoctonia solani Kuhn pathogenic to upland crops. Bull. Appointed. Exp., 7: l-131 